\title{
Validated stability indicating liquid chromatographic determination of ebastine in pharmaceuticals after pre column derivatization: Application to tablets and content uniformity testing
}

\author{
Fawzia Ibrahim, Mohie Khaled Sharaf El- Din, Manal Ibrahim Eid and Mary Elias Kamel Wahba*
}

\begin{abstract}
An accurate, simple, sensitive and selective reversed phase liquid chromatographic method has been developed for the determination of ebastine in its pharmaceutical preparations. The proposed method depends on the complexation ability of the studied drug with $\mathrm{Zn}^{2+}$ ions. Reversed phase chromatography was conducted using an ODS C18 (150 $\times$ $4.6 \mathrm{~mm}$ id) stainless steel column at ambient temperature with UV-detection at $260 \mathrm{~nm}$. A mobile phase containing $0.025 \% \mathrm{w} / \mathrm{V} \mathrm{Zn}^{2+}$ in a mixture of (acetonitril/methanol; 1/4) and Britton Robinson buffer (65:35, v/v) adjusted to $\mathrm{pH} 4.2$, has been used for the determination of ebastine at a flow rate of $1 \mathrm{ml} / \mathrm{min}$. The calibration curve was rectilinear over the concentration range of $0.3-6.0 \mu \mathrm{g} / \mathrm{ml}$ with a detection limit (LOD) of $0.13 \mu \mathrm{g} / \mathrm{ml}$, and quantification limit (LOQ) of $0.26 \mathrm{\mu g} / \mathrm{ml}$. The proposed method was successfully applied for the analysis of ebastine in its dosage forms, the obtained results were favorably compared with those obtained by a comparison method. Furthermore, content uniformity testing of the studied pharmaceutical formulations was also conducted. The composition of the complex as well as its stability constant was also investigated. Moreover, the proposed method was found to be a stability indicating one and was utilized to investigate the kinetics of alkaline and ultraviolet induced degradation of the drug. The first-order rate constant and half life of the degradation products were calculated.
\end{abstract}

\section{Background}

Ebastine; (4'-tert.-butyl-4-[4-(diphenylmethoxy)- piperidino]butyrophenone (Figure 1), is a potent and selective histamine $\mathrm{H}_{1}$-receptor antagonist in vivo, which has little anticholinergic and antiserotoninergic properties [1]. This agent also has no effects on cardiovascular and psychomotor functions, which occurred during treatment with classical antihistamine agents such as chlorpheniramine and diphenhydramine [1]. Literature survey reveals that the drug was determined by spectrofluorimetry [2], and by high performance liquid chromatography either alone in its dosage forms [3,4] or in presence of its metabolites $[5,6]$.

\footnotetext{
* Correspondence: marywahba2004@yahoo.com

* Correspondence: marywahba2004@yahoo.com
Department of Analytical Chemistry, Faculty of Pharmacy, Mansoura University, Mansoura, 35516, Egypt
} 


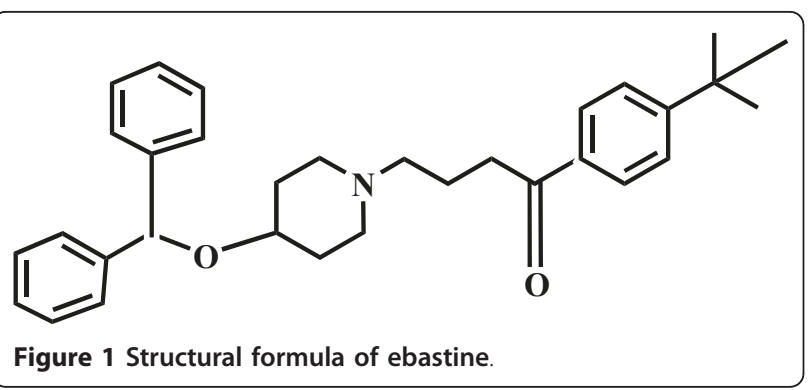

indicating property of the method, and its advantage over the previously reported HPLC methods $[3,4]$ in terms of its high sensitivity. Moreover, the method illustrates a full detailed study for the kinetic degradation of the drug applying the proposed method, where different kinetic parameters have been calculated.

\section{Experimental}

Materials and reagents

- Ebastine (EBS); of purity $99.94 \%$ was kindly provided by Meivo Pharmaceutical Company, Cairo, Egypt.

- Britton Robinson buffer was prepared [13] by mixing $0.03 \mathrm{M}$ of each of acetic acid, o-phosphoric acid and boric acid. The $\mathrm{pH}$ was adjusted using $0.2 \mathrm{M}$ sodium hydroxide.

- Methanol (Sigma-Aldrich), HPLC grade

- Acetonitrile (Sigma-Aldrich), HPLC grade.

- Sodium hydroxide (2M solution), hydrochloric acid (2M solution), hydrogen peroxide ( $6 \% \mathrm{v} / \mathrm{v}$ solution); (BDH, Poole, UK).

- Acetate buffer (pH 3.5 - 5.6) and borate buffers (pH 6 - 9) were prepared according to the British Pharmacopoeia [14].

- Zinc (II) chloride (BDH, Poole, UK), $1 \times 10^{-3} \mathrm{M}$ aqueous solution, were prepared in distilled water.

\section{Pharmaceutical preparations}

* Bastab ${ }^{\circledR}$ tablets (BN\#112038), labeled to contain $20 \mathrm{mg}$ ebastine/tablet, Meivo Pharmaceutical Company, Cairo, Egypt.

* Evastine ${ }^{\circledR}$ syrup (BN\# 94634), labeled to contain 5 mg ebastine $/ 5 \mathrm{ml}$, Marcyrl Pharmaceutical Industries, El Obour City, Egypt.

* Ebastel ${ }^{\mathbb{B}}$ tablets (BN\# 916201), labeled to contain 10 mg ebastine/tablet, Global Napi Pharmaeuticals, Cairo, Egypt.

All were obtained from commercial sources in the local market.

\section{Apparatus}

- Separation was performed with a Shimadzu C-R6A Chromatopac equipped with a Rheodyne injector valve with a $20 \mu \mathrm{L}$ loop and a UV/VIS detector.
- A Shimadzu UV 1601 PC Spectrophotometer equipped with a pair of $1 \mathrm{~cm}$ matched cells, recording range: $0-2$; wavelength: $200-400 \mathrm{~nm}$; factor:1; number of cells:1; cycle time:0.1 min was used.

- Mass spectroscopy was performed on DI Analysis Shimadzu QP-2010 Plus.

- Infra red spectroscopy was conducted using Mattson 5000 FITR Spectrometer.

- TLC aluminium sheets $20 \times 20$ silica gel 60 F254 for TLC were used.

\section{Columns and mobile phases}

Separation was achieved on an EC nucleosil C18-SN: 4115568 column $(150 \mathrm{~mm} \times 4.6 \mathrm{~mm}$ id $(5 \mathrm{~mm}) \mathrm{com}-$ bined with a guard column (Merck, Darmstadt, Germany). The columns were operated at ambient temperature. The analytical system was washed daily with $60 \mathrm{ml}$ of 1:1 mixtures of water and methanol to eliminate the mobile phase; this did not cause any change in the column performance. The mobile phase was prepared by mixing (acetonitrile/methanol; 1/4) with $0.03 \mathrm{M}$ Britton Robinson buffer in a ratio of $65: 35 \mathrm{v} / \mathrm{v}$ at $\mathrm{pH}$ of 4.2 . The mixture was then sonicated for 30 minutes. The resulting mobile phase was filtered through a $0.45 \mu \mathrm{m}$ membrane filter (Millipore, Ireland).

\section{Standard solutions}

A stock solution containing $10.0 \mathrm{mg} / \mathrm{ml}$ of EBS was prepared in methanol and further diluted with the same solvent to obtain the working concentration range for the spectrophotometric measurements, and diluted with the mobile phase for the HPLC measurements. This solution was found to be stable for at least two weeks when kept in the refrigerator.

A stock solution containing $1.0 \mathrm{mg} / \mathrm{ml}$ of cetirizine hydrochloride internal standard was prepared in methanol and further diluted with the mobile phase to obtain a final concentration of $15.0 \mu \mathrm{g} / \mathrm{ml}$.

\section{Calibration curve}

Aliquots of EBS working standard solution $(20 \mu \mathrm{g} / \mathrm{ml})$ covering the concentration range $(0.3-6.0 \mu \mathrm{g} / \mathrm{ml})$ were transferred into a series of $10 \mathrm{ml}$ volumetric flasks, 2.5 $\mathrm{ml}$ of acetate buffer $\mathrm{pH} 5$ were added, followed by 1.5 $\mathrm{ml}$ of $1 \times 10^{-3} \mathrm{M} \mathrm{ZnCl}_{2}$, mixed with $15 \mu \mathrm{g} / \mathrm{ml}$ aliquots of cetirizine hydrochloride and diluted with the mobile phase to the mark. Twenty $\mu \mathrm{L}$ aliquots were injected (in triplicates) and eluted with the mobile phase under the reported chromatographic conditions. The calibration curve was constructed by plotting the peak area ratio against the final concentration of the drug $(\mu \mathrm{g} / \mathrm{ml})$. Alternatively, the corresponding regression equation was derived. 


\section{Analysis of tablets}

Twenty tablets were weighed and pulverized. An accurately weighed quantity of the powder equivalent to 20 mg of EBS was transferred into a small conical flask, and extracted three successive times each with $30 \mathrm{ml}$ of methanol. The extract was filtered into $100 \mathrm{ml}$ volumetric flask. The conical flask was washed with few millilitres of methanol and completed to the mark with the same solvent. The procedure was followed as described under "Calibration Curve". The nominal contents of the tablets were calculated using either the calibration graph or the corresponding regression equation.

\section{Preparation of the degradation products}

For the kinetic study, $1 \mathrm{ml}$ aliquots of EBS standard solution were transferred into a series of $25 \mathrm{ml}$ volumetric flasks to obtain a final concentration of $400 \mu \mathrm{g} /$ $\mathrm{ml}$ where $2 \mathrm{M}$ sodium hydroxide, $2 \mathrm{M}$ hydrochloric acid, or $6 \%$ hydrogen peroxide were added to prepare the alkaline, acidic, or oxidative degradation products respectively. The solutions were left in a thermostatically controlled water bath at different temperature settings for a fixed time interval (15 minutes). Regarding the UV degradation, a methanolic solution of the studied drug was exposed to Deuterium lamp in a cabinet distance of $15 \mathrm{~cm}$ at room temperature, and aliquots of the hydrolyzed solutions were analyzed every 3 hours interval.

Aliquot volumes of the degraded solutions were transferred to a series of $10 \mathrm{ml}$ volumetric flasks and neutralized with $2 \mathrm{M}$ hydrochloric acid, or $2 \mathrm{M}$ sodium hydroxide for alkaline and acidic degradation respectively, and the steps were completed as described under "calibration curve". The absorption spectra were recorded at $260 \mathrm{~nm}, \log \mathrm{a} / \mathrm{a}-\mathrm{x}$ versus time (minutes) was plotted to get the reaction rate constant and the half life time $t_{1 / 2}$.

For HPLC measurements, the above solutions were completed to the volume with the mobile phase, and the material was tested for degradation by the apparent decrease in the peak area ratio of the formed complex which appears at 5.3 minute.

\section{Isolation of the formed complex}

The formed complex was successively isolated and purified by preparative TLC using methylenechloride: methanol $(90: 10 \mathrm{v} / \mathrm{v})$. The solvent was removed by evaporation under reduced pressure, and the purity of the complex was tested by TLC. The TLC was performed using chloroform: methanol $(75: 25 \mathrm{v} / \mathrm{v})$ as a developing solvent, where the $\mathrm{R}_{\mathrm{f}}$ of ebastine and EBS- $\mathrm{Zn}^{2+}$ complex were 0.74 and 0.55 respectively, which in turn confirms the completeness of the complex formation reaction.
After confirmation of the purity of the complex, infra red (IR) and mass spectroscopy (MS) were performed to elucidate the structure of the resultant product.

The IR spectrum of the studied complex shows the same bands of the main functional groups in ebastine; such as the stretching band of the C-N of the tertiary amine at $1361 \mathrm{~cm}^{-1}$, the stretching band corresponding to $\mathrm{C}=\mathrm{O}$ at $1677 \mathrm{~cm}^{-1}$, and also the ether $\mathrm{C}-\mathrm{O}$ band at $1072 \mathrm{~cm}^{-1}$ (Figure 2), which means that the aforementioned functional groups were not altered through the complexation reaction.

The MS spectrum of the complex (Figure 3) shows the molecular ion peak at $\mathrm{m} / \mathrm{z} 1070$, and putting in consideration that the molecular weight of ebastine is 470 [15]; the resultant spectrum confirms the reaction stoichiometry that two moles of EBS reacts with one mole of $\mathrm{Zn}^{2+}$. The molecular ion peak in turn is subjected to further fragmentation in the MS through breakage of the bonds formed between $\mathrm{Zn}^{2+}$ and each of the ether oxygen and the nitrogen atom of the tertiary amino group to yield a peak at $\mathrm{m} / \mathrm{z}$ of 470 ; while the fragments appearing at $\mathrm{m} / \mathrm{z} 161$ and 678 suggest fragmentation at the carbonyl atom (Scheme 1).

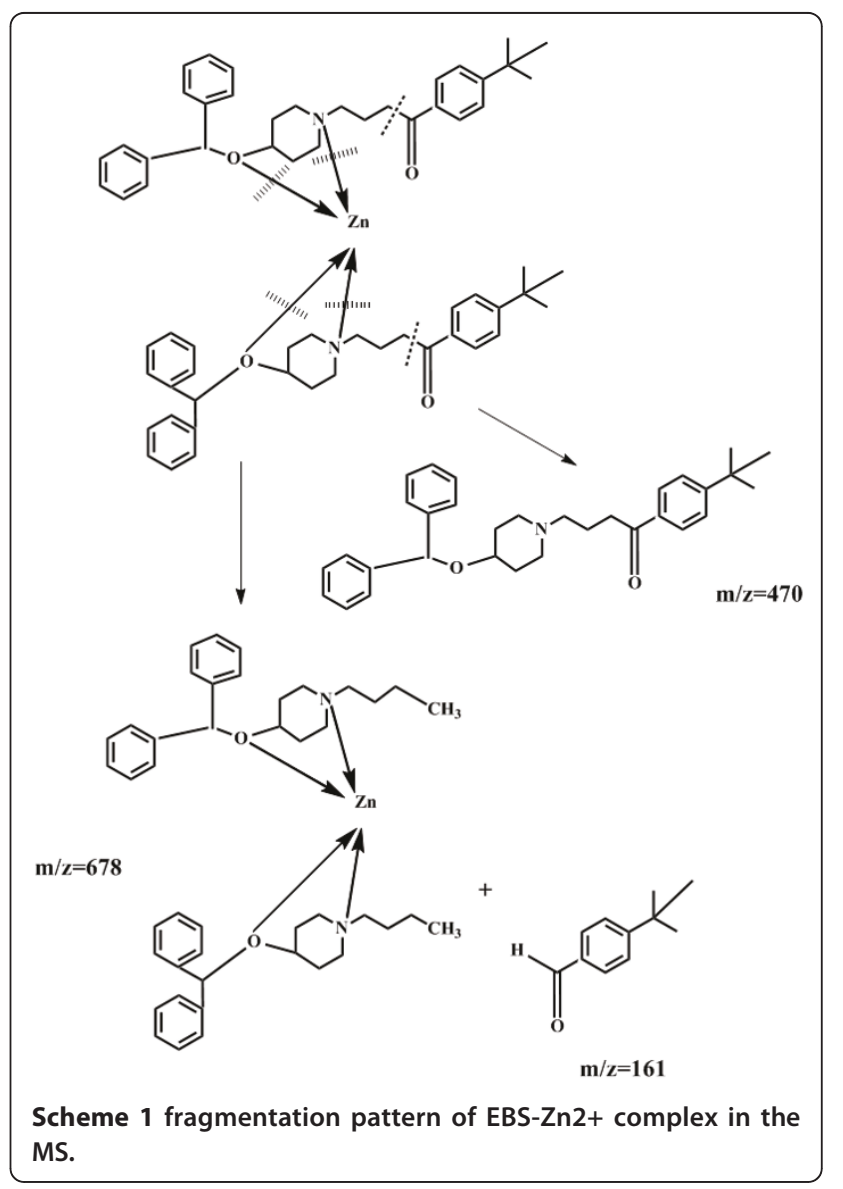


According to this interpretation, the reaction pathway was proposed to proceed as shown in scheme 2 .

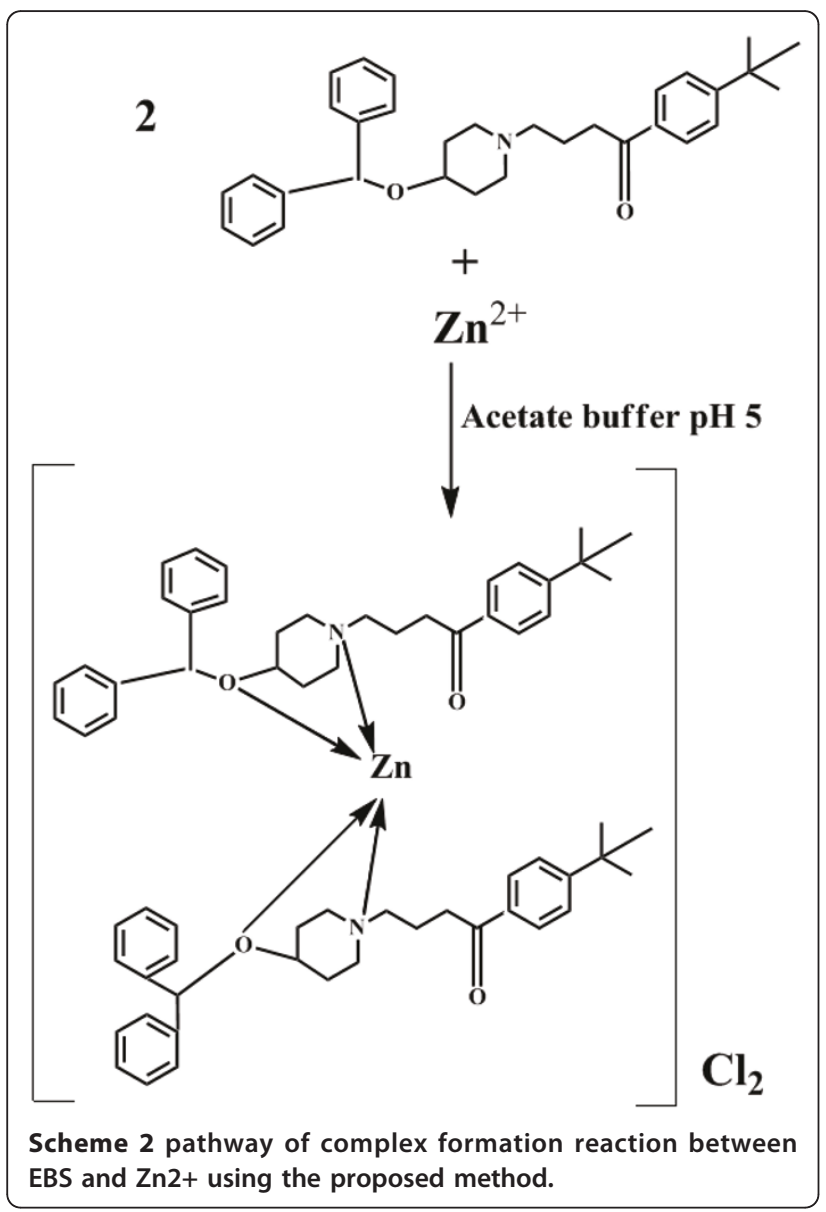

\section{Validation of the method}

The method was tested for linearity, sensitivity, accuracy, precision and robustness.

\section{Linearity}

The linearity of an analytical procedure is its ability (within a given range) to obtain test results which are directly proportional to the concentration of analyte in the sample [16]. Linearity of the proposed method was assessed by estimating the linear dependence of the obtained peak area ratios on the concentration of EBS.

\section{Sensitivity}

Detection limit (LOD) is the lowest concentration of the drug that can be detected, but not necessarily quantitated, under the stated experimental conditions. The limit of detection is generally quoted as the concentration yielding a signal-to-noise ratio of $3: 1$ [17] and is confirmed by analyzing a number of samples near this value using the following equation:

$$
\text { The signal }- \text { to }- \text { noise ratio } \mathrm{s}=\mathrm{H} / \mathrm{h}
$$

Where $\mathrm{H}=$ height of the spectrum corresponding to the drug

$\mathrm{h}=$ absolute value of the largest noise fluctuation from the baseline of the spectrum of a blank solution.

While the limit of quantification (LOQ); is the lowest concentration of the analyte that can be determined with acceptable precision and accuracy. It is quoted as the concentration yielding a signal-to-noise ratio of 10 : 1 and is confirmed by analyzing a number of samples near this value [17].

\section{Accuracy}

The accuracy of an analytical procedure expresses the closeness of agreement between an accepted reference value and the value found [16]. The accuracy of the proposed method was evaluated by analyzing standard solutions of EBS. The results obtained by the proposed method were favorably compared with those obtained by the comparison method [4].

\section{Precision}

The precision of an analytical procedure expresses the closeness of agreement between a series of measurements obtained from multiple sampling of the same homogeneous sample under the prescribed conditions. Precision may be considered through repeatability and intermediate precision [16].

\section{Repeatability}

Repeatability expresses the precision under the same operating conditions over a short interval of time. Repeatability is also termed intra-assay precision [16]. The repeatability was evaluated through the replicate analysis of different concentrations of EBS samples, either in pure or in dosage forms.

\section{Intermediate precision}

Intermediate precision expresses within-laboratories variations: different days, different analysts, different equipment, etc. [16]. It was performed through replicate analysis of different concentrations of EBS samples, either in pure or dosage form on four successive days.

\section{Robustness of the method}

The robustness of an analytical procedure is a measure of its capacity to remain unaffected by small, but deliberate variations in method parameters and provides an indication of its reliability during normal usage [16]. The robustness of the adopted method was demonstrated by the consistency of the values of the peak area ratios with the deliberately minor changes in the 


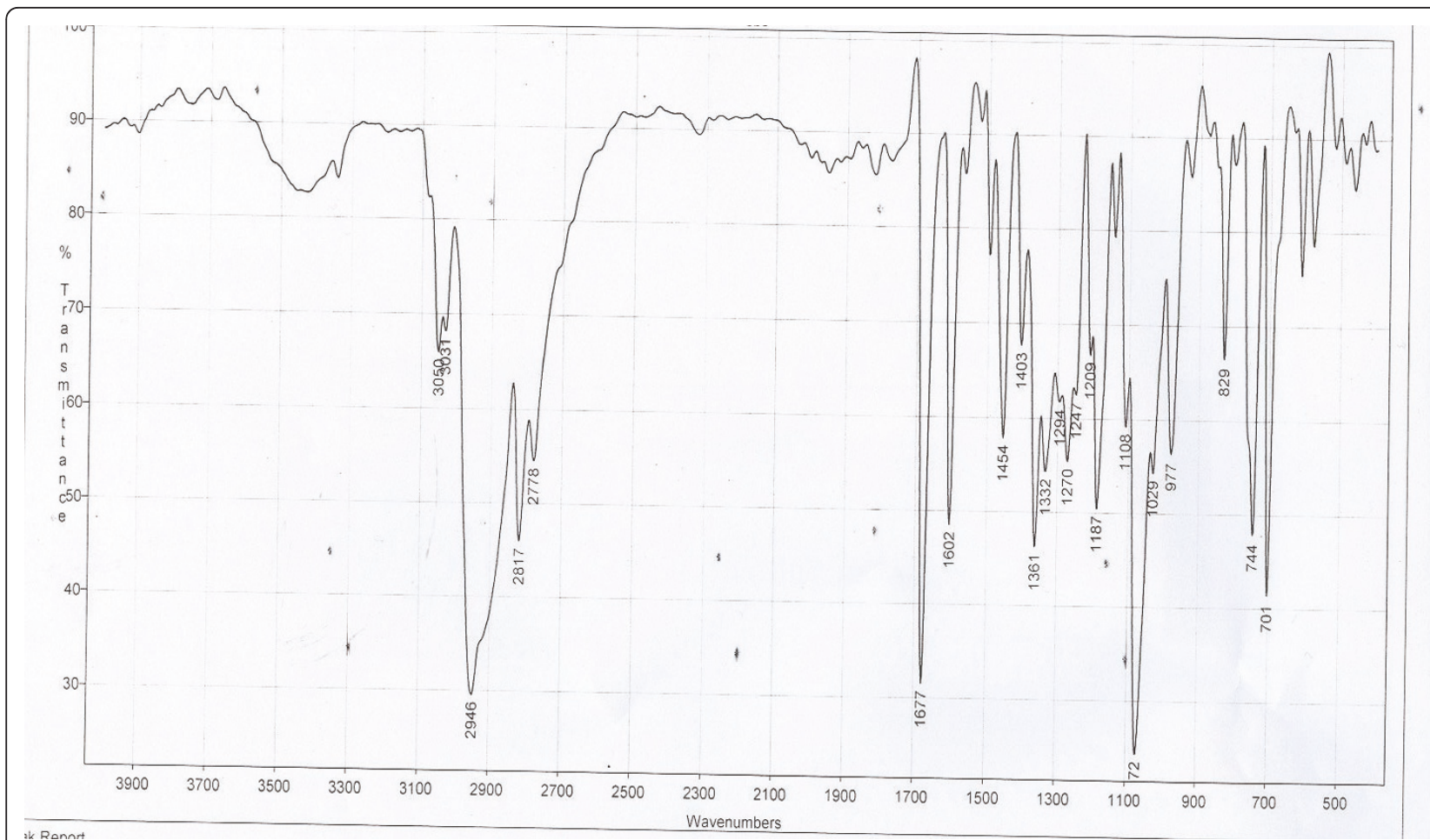

Figure 2 IR spectrum of EBS $-\mathrm{Zn}^{2+}$ complex

experimental parameters such as, Britton Robinson buffer of pH 4-4.5 and $(0.015 \mathrm{M}-0.05 \mathrm{M})$ molar strength, and organic phase: buffer ratio (65:35-70:30) v/v which did not greatly affect the peak area ratios.

\section{Results and discussion}

Ebastine is a weakly absorbing drug having a molar absorptivity of $9.4 \times 10^{2} \mathrm{~L}$. mole ${ }^{-1} \mathrm{~cm}^{-1}$. In the present study, EBS was found to form a highly stable complex with zinc (II); the complex was found to be formed instantaneously in the presence of acetate buffer of $\mathrm{pH} 5$ and has molar absorptivity of $7.6 \times 10^{4} \mathrm{~L}$. mole ${ }^{-1} \mathrm{~cm}^{-1}$. The absorption spectrum of the complex showed a maximum absorbance at $260 \mathrm{~nm}$ (Figure 4).

Separation of the formed complex (Figure 5) was achieved using a mobile phase consisting of a mixture

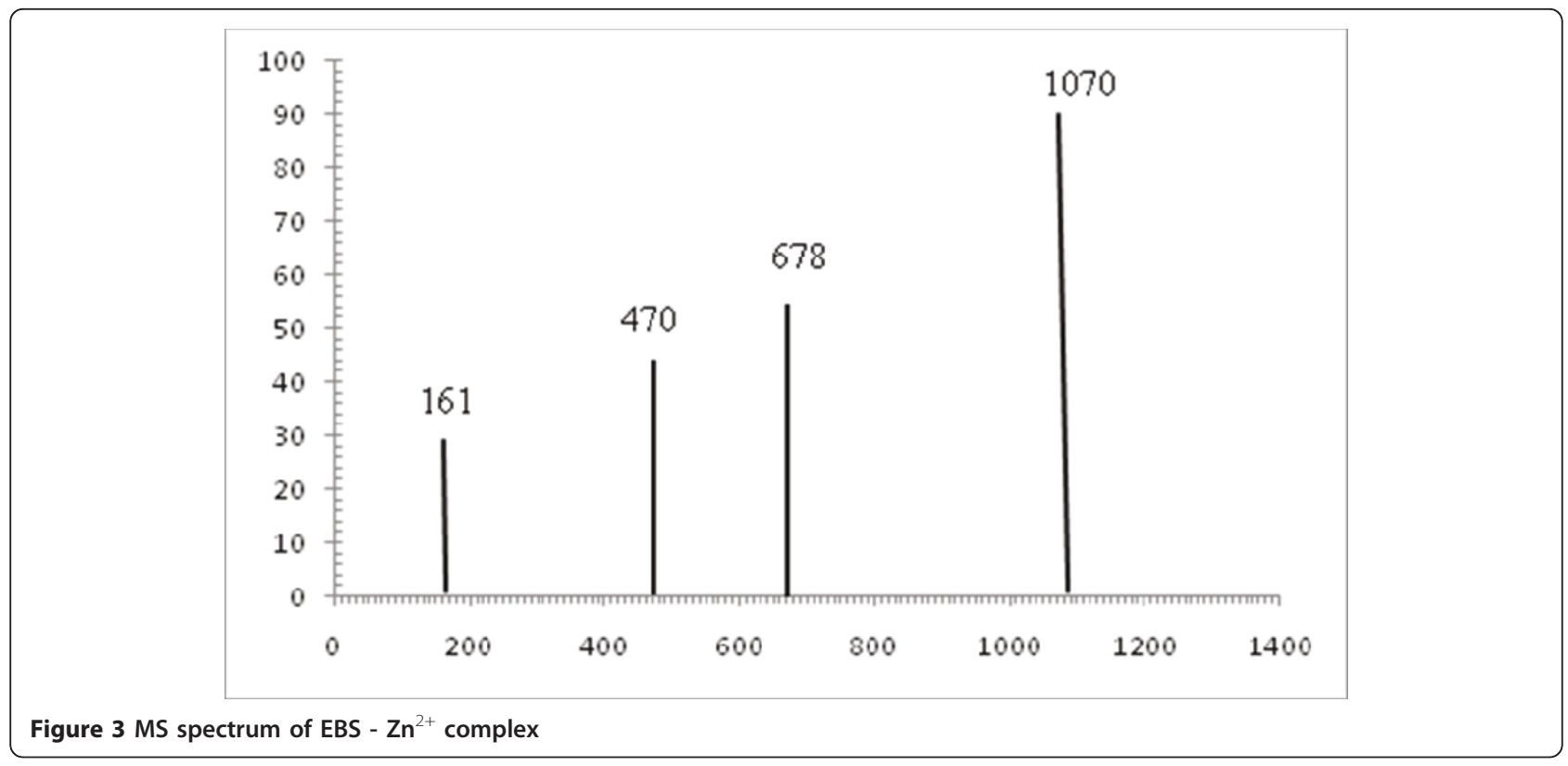




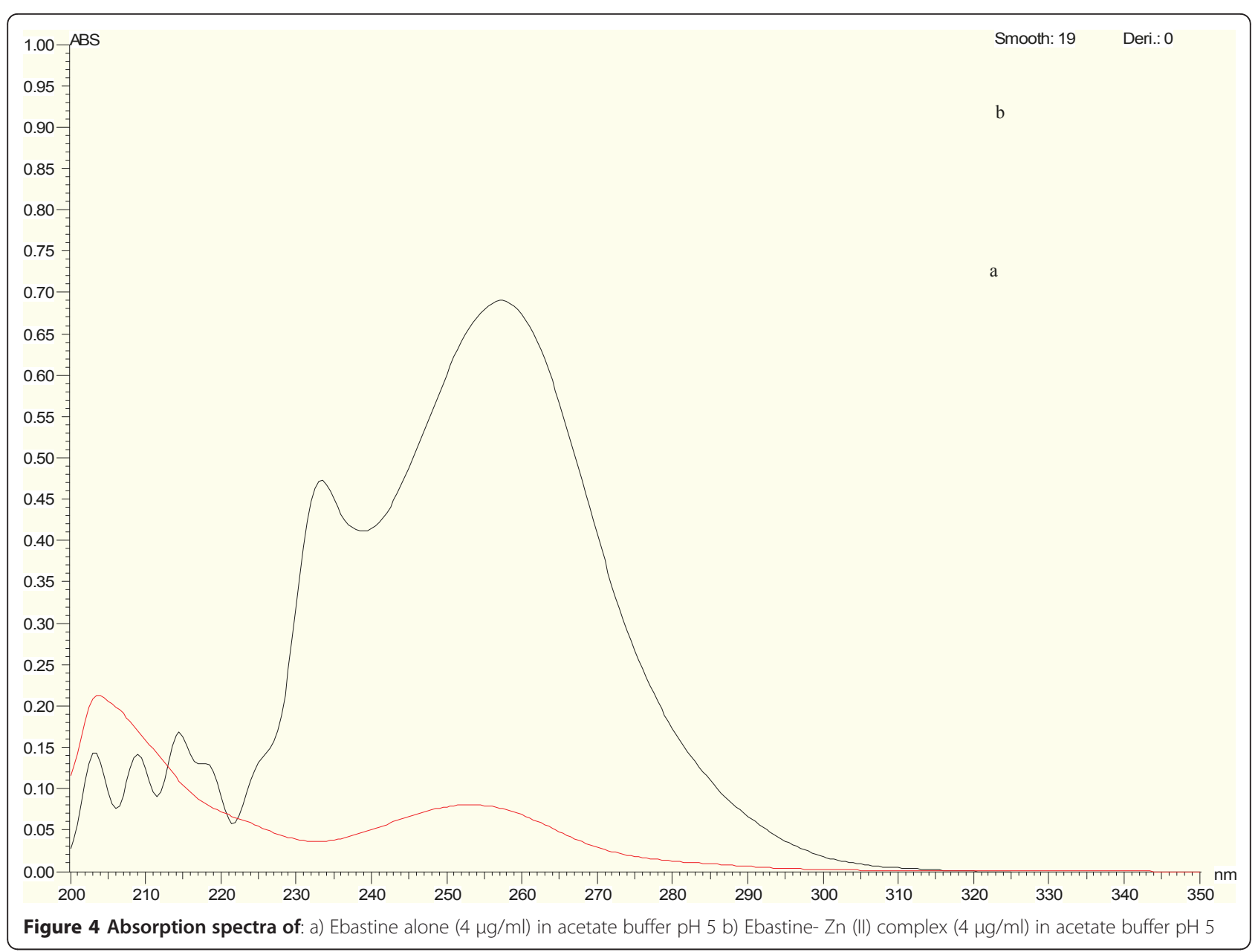

of (acetonitrile/methanol; 1/4) and $0.03 \mathrm{M}$ Britton Robinson buffer in a ratio of $65: 35 \mathrm{v} / \mathrm{v}$ and adjusted to $\mathrm{pH}$ 4.2. The mobile phase was chosen after several trials with various proportions of the buffer and the organic phase at different $\mathrm{pH}$ values. Under the described chromatographic conditions complete base line separation with satisfactory resolution between the peaks was achieved in a short chromatographic run; less than 6 minutes. The proposed method was assessed for selectivity, linearity, precision, accuracy, and stability.

The different experimental parameters affecting the separation selectivity of the liquid chromatographic system have been investigated and optimized. Hence, the method was applied to the determination of EBS in its tablets, and further for content uniformity testing.

\section{Optimization of the reaction conditions}

The spectral properties of the formed complex as well as the different experimental parameters affecting its development and stability were carefully studied and optimized; such factors were changed individually while the others were kept constant. After which a detailed study for choosing the composition of the mobile phase was carried out for the optimum separation of the resultant complex.

\section{Optimization of the reaction conditions required for complex formation}

The effect of addition order on the absorbance value of the system was studied. The results showed that the addition order of EBS - acetate buffer - metal was the best regarding absorbance intensity reading.

Using different types of buffers such as phosphate or citrate having the same $\mathrm{pH}$ values selected for the proposed method gave the same results; however, acetate buffer was chosen throughout the study since no interference in the results was noticed as in the case of other buffers. The influence of $\mathrm{pH}$ on the absorbance value of the formed complex was investigated over the $\mathrm{pH}$ range 3.5 - 5.6 using acetate buffer and from $6-9$ using borate buffers. Maximum and constant absorbance value was achieved at $\mathrm{pH}$ (4.5-5.5) using $2.5 \mathrm{ml}$ of acetate buffer. Therefore, acetate buffer of $\mathrm{pH} 5$ was used. 


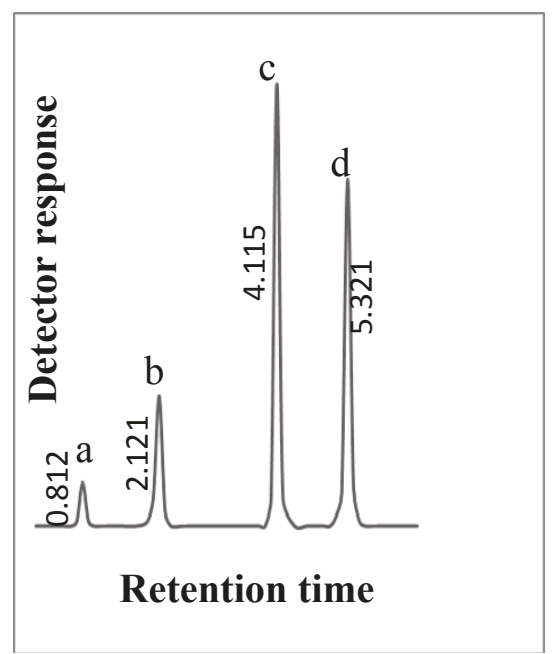

A

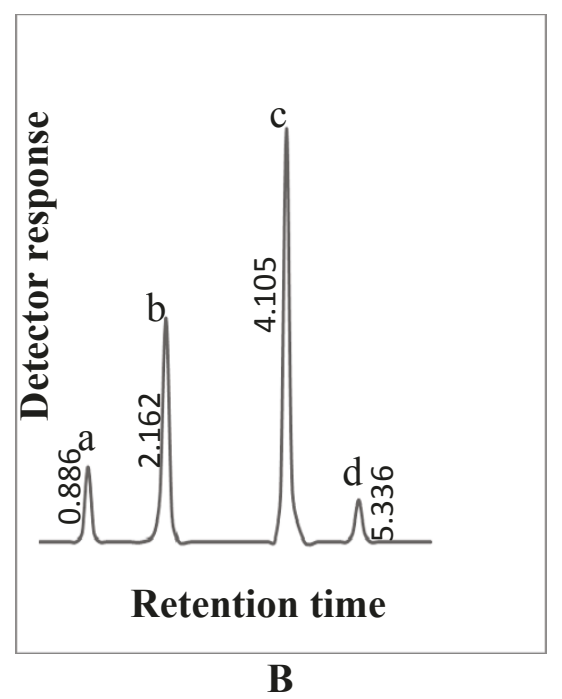

Figure 5 Typical chromatograms showing ebastine alone and after complexation. A. Typical chromatogram showing EBS-Zn (II) complex at $\mathbf{2 6 0} \mathbf{n m}$ where: a) Solvent front b) Zn (II) $0.0025 \%$ c) Cetirizine hydrochloride internal standard $(15 \mu \mathrm{g} / \mathrm{ml})$. d) EbastineZn (II) complex; (EBS $=4 \mu \mathrm{g} / \mathrm{ml}$ ) B. A chromatogram showing ebastine alone at $\mathbf{2 6 0} \mathbf{n m}$ where: a) Solvent frontb) $\mathrm{Zn}$ (II) $0.0025 \%$ c) Cetirizine hydrochloride internal standard $(15 \mu \mathrm{g} / \mathrm{ml})$. d) Ebastine alone $(4 \mathrm{\mu g} / \mathrm{ml})$

The effect of volume of acetate buffer of pH 5 was also studied keeping the concentrations of the drug and the metal constant. It was found that increasing the volume of acetate buffer ( $\mathrm{pH}$ 5) resulted in a subsequent increase in the absorbance value of the formed complex up to $2 \mathrm{ml}$, after which the absorbance remained constant. Therefore $2.5 \pm 0.5 \mathrm{ml}$ of acetate buffer of $\mathrm{pH} 5$ was chosen as the optimum volume of the buffer throughout this approach.
It was found that increasing the volume of $\mathrm{Zn}$ (II) $(1 \times$ $10^{-3} \mathrm{M}$ ) resulted in a gradual increase in the absorbance value of the complex up to $1 \mathrm{ml}$, after which it remained constant, therefore, $1.5 \pm 0.5 \mathrm{ml}$ of $\left(1 \times 10^{-3} \mathrm{M}\right)$ was chosen.

The reaction was carried out at different temperature settings (room temperature, 40,60, $80,100^{\circ} \mathrm{C}$ ) using a thermostatically controlled water bath. Maximum absorbance values were obtained at room temperature.

Different types of surfactants, such as sodium lauryl sulphate (anionic type), gelatin, and methyl cellulose (non ionic types) were added to the reaction mixture to test their effect on the absorbance value of the formed complex hoping that they may enhance the absorbance readings, but it was found that all the studied surfactants had no significant effect on the absorbance value of the formed complex, hence the complex formation was carried out without their addition. Similarly different sensitizers were tested such as quinine, fluorescein and rhodamine-B. Addition of sensitizers to the reaction mixture was found to enhance the absorbance but with the lack of reproducibility. Therefore, the study was carried out without the addition of sensitizers.

The effect of ionic strength on the absorbance readings was followed by adding different concentrations of $\mathrm{KCl}(0.01-0.1 \mathrm{M})$, which revealed that $\mathrm{KCl}$ did not have any significant effect on the formation of the studied complex.

The formation and stability of the formed complex was also studied by measuring the absorbance readings every 10 minutes interval, the consistency of the absorbance values indicated that EBS-Zn (II) complex was formed instantaneously and remained stable for at least 90 minutes.

\section{Reaction stoichiometry}

The stoichiometry of the reaction between EBS and Zn (II) was determined spectrophotometrically by applying Job's continuous variation method [18], where the plot reached a maximum value at a mole fraction of 0.6 , which indicated the formation of a 2:1 EBS : Zn (II) complex.

The formation constant of the reaction product was calculated according to the following equation [19]:

$$
\mathrm{K}_{\mathrm{f}}=\frac{\mathrm{A} / \mathrm{Am}}{\left[(1-\mathrm{A} / \mathrm{Am})^{\mathrm{n}+1}\right] \mathrm{c}^{\mathrm{n}} \mathrm{n}^{\mathrm{n}}}
$$

where $A$ and $A_{m}$ are the observed maximum absorbance and the absorbance obtained from the extrapolation of the two lines obtained from Job's continuous variation method, respectively; $\mathrm{n}$ is the number of moles of $\mathrm{Zn}^{2+}$ involved in the complex formation reaction ; $\mathrm{n}$ 
$=1$; $\mathrm{C}$ is the molar concentration of the drug used in Job's continuous variation method.

Using the above equation $\mathrm{K}_{\mathrm{f}}$ was found to be $5.2 \times$ $10^{5}$

Also, the Gibbs free energy changes $(\Delta G)$ of the reaction were calculated according to the following equation [19]:

$$
\Delta \mathrm{G}=-2.303 \mathrm{RT} \quad \log \mathrm{K}_{\mathrm{f}}
$$

Where $\mathrm{R}$ is gas constant $=8.3$ joule.degree ${ }^{-1} \cdot \mathrm{mole}^{-1} ; \mathrm{T}$ is temperature (K).

Using the above equation $\Delta \mathrm{G}$ was found to be $-2.4 \times$ $10^{3}$ Joule/Mole.

The high negative value of $\Delta \mathrm{G}$ indicates that the reaction is spontaneous.

\section{Chromatographic performances}

A well-defined symmetrical peak was obtained upon measuring the response of the eluent under the performance parameters after thorough experimental trials that could be summarized as follows:

\section{Ratio of aqueous: organic phase}

The effect of Britton Robinson buffer: organic phase; (acetonitrile-methanol mixture) ratio on the separation of the formed complex was studied. Satisfactory separation was obtained with a mobile phase consisting of Britton Robinson buffer $\mathrm{pH}$ 4.2: organic phase (35:65$30: 70 \mathrm{v} / \mathrm{v})$ at ambient temperature. At lower organic phase concentrations $(<65 \%)$; decrease in the number of theoretical plates (NTP) and peak area ratios was observed.

\section{Ratio of acetonitrile: methanol in the organic phase}

The influence of the ratio of acetonitrile: methanol in the organic portion of the mobile phase was followed. Adequate resolution without peak tailing and maximum peak area ratios resulted when the organic phase was composed of acetonitrile : methanol in a ratio of 1:4.

\section{Effect of $\mathrm{pH}$}

The $\mathrm{pH}$ of the mobile phase was investigated through $\mathrm{pH}$ from 3 to 6 . It was found that proper resolution with highest NTP and peak area ratios was achieved at $\mathrm{pH} 4-4.5$. When the $\mathrm{pH}$ was lower than 4 , remarkable decrease in NTP with slight reduction in peak area ratios resulted, while at $\mathrm{pH}$ higher than 4.5, sharp decrease in the latter two parameters occurred.

\section{Effect of buffer type}

Different buffers of the same pH (4.2) were also studied. Phosphate and acetate buffer resulted in peaks lacking symmetry and in lower values of NTP and peak area ratios than those obtained by Britton Robinson buffer.

\section{Effect of molar strength of Britton Robinson buffer}

The effect of different molar strengths of Britton Robinson buffer ( $\mathrm{pH} 4.2)$ over the range (0.0075-0.1 M) on the separation of the formed complex was investigated. It was found that (0.015-0.05 M) Britton Robinson buffer gave the highest NTP and peak area ratios. A gradual decrease in the previously mentioned parameters was observed when the molar strength was either lower than $0.015 \mathrm{M}$ or higher than $0.05 \mathrm{M}$. Furthermore, alteration of the peak symmetry of the resultant complex was remarkably observed at the higher molar strength.

\section{Effect of Zn (II) concentration}

The presence of $\mathrm{Zn}$ (II) in the mobile phase was essential to prevent the hydrolysis of the formed complex. In the absence of $\mathrm{Zn}$ (II) in mobile phase a very small peak area ratios was obtained, so a mobile phase containing $0.0025 \%$ of $\mathrm{Zn}$ (II) was chosen for good formation and separation of the formed complex (Figure 6).

\section{Effect of different types of columns}

Different types of columns were tried to perform the separation of EBS-Zn (II) complex. Successful separation process was achieved by the EC nucleosil C18-SN : 4115568 column; on the other hand, it was found that upon using Hibar prepacked column RT-250-4-L-100RP8 distorted peaks were obtained, while Zorbax ${ }^{\circledR}$ SBPhenyl column $(250 \mathrm{~mm} \times 4.6 \mathrm{~mm}$ id $(5 \mathrm{~mm})$ resulted in well separated peaks but with longer retention times.

\section{Effect of detector wavelength}

The UV detector response of the complex was studied from the range of $220-280 \mathrm{~nm}$, and the best wavelength was found to be $260 \mathrm{~nm}$ showing highest sensitivity and appreciable absorbance of EBS-Zn (II) complex.

\section{Effect of flow rate}

The effect of different flow rates $(0.6-1.5 \mathrm{ml} / \mathrm{min})$ on the separation of the complex was tested, and it was found that $1 \mathrm{ml} / \mathrm{min}$ was the most suitable flow rate regarding the retention times and the symmetry of the peaks.

A collective study of experimental parameters affecting the chromatographic separation is summarized in Table 1.

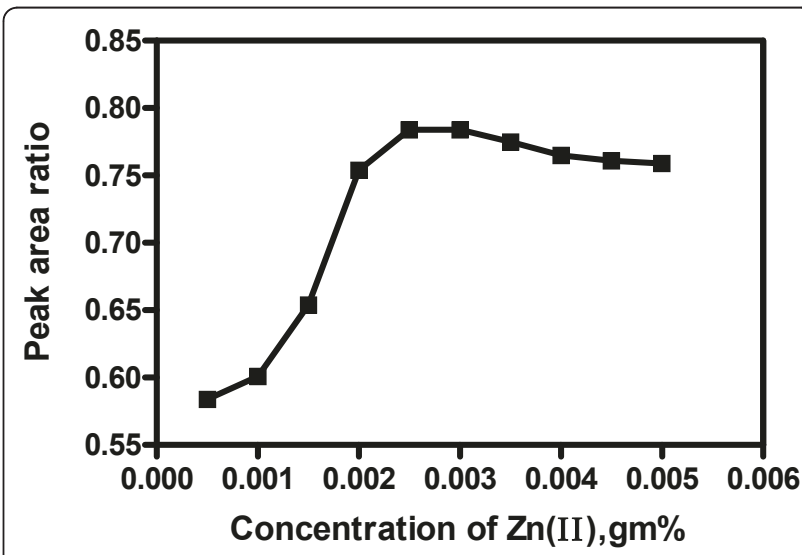

Figure 6 Effect of concentration of $\mathrm{Zn}$ (II) in the mobile phase on the peak area ratios of the formed complex. 
Table 1 Effect of experimental parameters on the separation of EBS-Zn (II) complex

\begin{tabular}{|c|c|c|c|c|c|}
\hline Parameter & $\mathrm{K}^{\prime}$ & $\mathrm{N}$ & HETP & Rs & Peak area ratio \\
\hline \multicolumn{6}{|c|}{ Buffer type and $\mathrm{pH}$} \\
\hline \multicolumn{6}{|l|}{ Britton Robinson buffer pH } \\
\hline 3 & 3.41 & 1036 & 0.0145 & 2.73 & 0.726 \\
\hline 3.5 & 3.92 & 1034 & 0.0145 & 3.58 & 0.743 \\
\hline 4 & 5.53 & 2706 & 0.0055 & 5.012 & 0.784 \\
\hline 4.5 & 5.13 & 2698 & 0.0055 & 5.012 & 0.784 \\
\hline 5 & 3.84 & 1507 & 0.0099 & 4.177 & 0.752 \\
\hline 5.5 & 3.66 & 769 & 0.0195 & 3.166 & 0.688 \\
\hline 6 & 3.76 & 258 & 0.0581 & 3.133 & 0.564 \\
\hline Phosphate buffer pH 4.2 & 4.26 & 1479 & 0.0101 & 2.72 & 0.366 \\
\hline Acetate buffer pH 4.2 & 4.06 & 1027 & 0.0146 & 1.271 & 0.521 \\
\hline \multicolumn{6}{|c|}{ Ratio of aqueous: organic phase(acetonitril: methanol; 1:4) } \\
\hline 45:55 & 4.02 & 837 & 0.0179 & 1.088 & 0.29 \\
\hline $40: 60$ & 4.25 & 1034 & 0.0145 & 4.15 & 0.45 \\
\hline $35: 65$ & 5.53 & 2706 & 0.0055 & 5.012 & 0.784 \\
\hline $30: 70$ & 5.52 & 2687 & 0.0056 & 5.009 & 0.783 \\
\hline \multicolumn{6}{|c|}{ Ratio of acetonitril: methanol } \\
\hline $1: 4$ & 5.53 & 2706 & 0.0055 & 5.012 & 0.784 \\
\hline $2: 3$ & 3.52 & 1210 & 0.0124 & 3.64 & 0.645 \\
\hline $3: 2$ & 2.73 & 2205 & 0.0068 & 4.45 & 0.429 \\
\hline $4: 1$ & 4.103 & 1393 & 0.0108 & 4.41 & 0.235 \\
\hline Acetonitril only & 5.08 & 1347 & 0.0111 & 4.745 & 0.198 \\
\hline Methanol only & 4.938 & 1817 & 0.0083 & 4.371 & 0.349 \\
\hline \multicolumn{6}{|c|}{ lonic strength of BRb (Molar) } \\
\hline 0.0075 & 4.256 & 911 & 0.0165 & 3.714 & 0.48 \\
\hline 0.01 & 5.23 & 1895 & 0.0079 & 4.015 & 0.69 \\
\hline 0.015 & 5.53 & 2706 & 0.0055 & 5.012 & 0.784 \\
\hline 0.02 & 5.52 & 2716 & 0.0053 & 5.009 & 0.782 \\
\hline 0.05 & 5.55 & 2720 & 0.0052 & 5.011 & 0.783 \\
\hline 0.07 & 4.62 & 1816 & 0.0083 & 4.127 & 0.642 \\
\hline 0.1 & 4.67 & 1173 & 0.0128 & 4.143 & 0.513 \\
\hline \multicolumn{6}{|c|}{ Flow rate (mL/minute) } \\
\hline 0.6 & 4.348 & 466 & 0.0322 & 2.11 & 0.92 \\
\hline 0.7 & 4.291 & 1013 & 0.0148 & 2.64 & 0.84 \\
\hline 0.8 & 4.342 & 1070 & 0.0141 & 2.69 & 0.75 \\
\hline 1 & 5.53 & 2706 & 0.0055 & 5.012 & 0.784 \\
\hline 1.1 & 5.26 & 1982 & 0.0076 & 4.857 & 0.662 \\
\hline 1.2 & 4.74 & 1486 & 0.0101 & 4.33 & 0.679 \\
\hline 1.3 & 4.25 & 1057 & 0.0142 & 3.21 & 0.54 \\
\hline 1.4 & 4.12 & 1013 & 0.0148 & 2.94 & 0.49 \\
\hline 1.5 & 3.97 & 925 & 0.0162 & 2.76 & 0.33 \\
\hline
\end{tabular}

Where:

$K^{\prime}$ is the capacity factor; $K^{\prime}=t_{R}-t_{M} / t_{M}$

$\mathrm{N}$ is the number of theoretical plates; $\mathrm{N}=\frac{5.55 t_{R}^{2}}{\mathrm{w}^{2}}$

HETP is the height equivalent to a theoretical plate; HETP $=\mathrm{L} / \mathrm{N}$

Rs is the resolution factor; $R s=\frac{2\left[t_{R}-t_{M}\right]}{w_{R}+w_{M}}$

$\left(t_{R}\right.$ is the retention time of the complex, $t_{M}$ is the time from injection to the appearance of the solvent front, $w_{1 / 2}$ is the peak width at half height, $L$ is the length of the column, $W_{R}$ and $w_{M}$ are the peak width at base line for the complex and the solvent front respectively) 
Table 2 Performance data of the proposed method

\begin{tabular}{cc}
\hline Parameter & Value \\
\hline Concentration range $(\boldsymbol{\mu g} / \mathrm{ml})$ & $0.3-6.0$ \\
\hline $\operatorname{LOD}(\boldsymbol{\mu g} / \mathbf{m l})$ & 0.13 \\
\hline $\mathbf{L O Q}(\boldsymbol{\mu g} / \mathbf{m l})$ & 0.26 \\
\hline Correlation coefficient $(\mathbf{r})$ & 0.9999 \\
\hline Slope & 0.1975 \\
\hline Intercept & $4.78 \times 10^{-4}$ \\
\hline $\mathbf{S}_{\mathbf{a}, \text { Standard deviation of the intercept of the regression line }}$ & $7.49 \times 10^{-5}$ \\
\hline $\mathbf{S}_{\mathbf{b}, \text { Standard deviation of the slope of the regression line }}$ & $1.49 \times 10^{-4}$ \\
\hline
\end{tabular}

\section{Analytical performance and applications}

\section{Validation of the method}

By using the above liquid chromatographic method, linear regression equation was obtained. The regression plot showed that, there was a linear dependence of the peak area ratio on the concentration of the drug over the working concentration range. The validity of the proposed method was evaluated by statistical analysis of the regression data (Table 2) regarding the standard deviation of the residuals $\left(\mathrm{S}_{\mathrm{y} / \mathrm{x}}\right)$, the standard deviation of the intercept $\left(\mathrm{S}_{\mathrm{a}}\right)$, and standard deviation of the slope $\left(S_{b}\right)$ [20]. The small values of the figures point to the low scattering of the points around the calibration graph and high precision of the proposed method

Linearity

The peak area ratio of EBS varied linearly with the concentration over the range $0.3-6 \mathrm{mg} / \mathrm{ml}$ as mentioned in Table 2 .
Linear regression analysis of the data gave the following equation:

$$
\mathrm{P}=0.1975 \mathrm{C}+4.78 \times 10^{-4}(\mathrm{r}=0.9999)
$$

Where $\mathrm{C}$ is the concentration in $\mathrm{mg} / \mathrm{ml}$ and $\mathrm{P}$ is the peak area ratio.

\section{Sensitivity}

The calculated values of LOQ and LOD are listed in Table 2.

The linear dependence of the peak area ratio versus the concentration of the drug was shown by calculation of the regression equation previously mentioned

\section{Accuracy}

Statistical analysis [20] of the results obtained by the proposed and comparison methods using student's t-test and variance ratio F- test, showed no significant difference between the performance of the two methods regarding the accuracy and precision, respectively (Table 3 ). The comparison method is based on an HPLC measurement of EBS using a mobile phase consisting of methanol: water (90:10, v/v/v) with UV detection at $262 \mathrm{~nm}$.

\section{Precision}

\section{Repeatability}

The mean percentage recoveries based on the average of four separate determinations for pure and dosage forms are abridged in Table 4.

Intermediate precision

The percentage recoveries are based on the average of four separate determinations. The results are shown in Table 4.

\section{Pharmaceutical applications}

Dosage forms analysis

The proposed method was successfully applied to the determination of EBS in its dosage forms. The average

Table 3 Application of the proposed method for the analysis of ebastine in pure form

\begin{tabular}{|c|c|c|c|}
\hline & Proposed method & & Comparison method [4] \\
\hline Amount taken $(\mu \mathrm{g} / \mathrm{ml})$ & Amount found $(\mu \mathrm{g} / \mathrm{ml})$ & $\%$ Recovery & $\%$ Recovery \\
\hline 0.3 & 0.2976 & 99.21 & 100.62 \\
\hline 0.5 & 0.5031 & 100.62 & 99.15 \\
\hline 0.7 & 0.7030 & 100.43 & 99.34 \\
\hline 1.0 & 0.9972 & 99.72 & \\
\hline 2.0 & 2.0148 & 100.74 & \\
\hline 3.0 & 3.0072 & 100.24 & \\
\hline 4.0 & 3.9912 & 99.78 & \\
\hline 5.0 & 4.981 & 99.62 & \\
\hline 6.0 & 6.0264 & 100.44 & \\
\hline $\mathrm{X}^{-} \pm \mathrm{SD}$ & & $100.09 \pm 0.52$ & $99.70 \pm 0.79$ \\
\hline Student's $\mathrm{t}$ test & & $0.61(1.86)^{*}$ & \\
\hline Variance ratio $\mathrm{F}$ test & & $2.3(5.25)^{*}$ & \\
\hline
\end{tabular}

*Figures between parentheses are the tabulated $t$ and $F$ values at $p=0.05$ [20].* 
Table 4 Validation of the proposed HPLC method for determination of ebastine in pure and dosage forms

\begin{tabular}{|c|c|c|}
\hline Preparation & Repeatability, \% Recovery & Intermediate precision, \%Recovery \\
\hline \multirow[t]{5}{*}{ Ebastine pure form } & Ebastine $(5.0 \mu \mathrm{g} / \mathrm{ml})$ & Ebastine $(6.0 \mu \mathrm{g} / \mathrm{ml})$ \\
\hline & 99.95 & 100.95 \\
\hline & 100.25 & 100.38 \\
\hline & 100.54 & 99.65 \\
\hline & 100.87 & 99.12 \\
\hline $\mathrm{X}^{-} \pm \mathrm{SD}$ & $100.41 \pm 0.39$ & $100.03 \pm 0.81$ \\
\hline \multirow[t]{5}{*}{ Bastab $^{\circledR}$ tablets } & Ebastine $(0.3 \mu \mathrm{g} / \mathrm{ml})$ & Ebastine $(4.0 \mu \mathrm{g} / \mathrm{ml})$ \\
\hline & 99.65 & 99.35 \\
\hline & 99.84 & 99.98 \\
\hline & 100.58 & 100.87 \\
\hline & 100.68 & 100.92 \\
\hline$X^{-} \pm S D$ & $100.19 \pm 0.52$ & $100.28 \pm 0.76$ \\
\hline \multirow[t]{5}{*}{ Evastine $^{\mathscr{0} \text { syrup }}$} & Ebastine $(2.0 \mu \mathrm{g} / \mathrm{ml})$ & Ebastine $(3.0 \mu \mathrm{g} / \mathrm{ml})$ \\
\hline & 100.14 & 99.32 \\
\hline & 100.55 & 100.84 \\
\hline & 100.92 & 100.99 \\
\hline & 99.64 & 100.06 \\
\hline $\mathrm{X}^{-} \pm \mathrm{SD}$ & $100.31 \pm 0.55$ & $100.31 \pm 0.77$ \\
\hline
\end{tabular}

percentages found of different concentrations were based on the average of three replicate determinations. The results shown in Table 5 are in good agreement with the comparison method [4].

\section{Content uniformity testing}

Due to the high precision of the method, and its ability to rapidly estimate the concentration of the drug in a single tablet extract with sufficient accuracy, the method is suited for content uniformity testing which is a time

Table 5 Determination of ebastine in its dosage forms by the proposed HPLC method

\begin{tabular}{|c|c|c|c|c|}
\hline \multicolumn{4}{|c|}{ Proposed method } & \multirow{2}{*}{$\begin{array}{c}\text { Comparison method [4] } \\
\% \text { Recovery }\end{array}$} \\
\hline Preparation & Amount taken $(\mu \mathrm{g} / \mathrm{ml})$ & Amount found $(\mu \mathrm{g} / \mathrm{ml})$ & \% Recovery & \\
\hline \multirow[t]{6}{*}{ Bastab $^{\circledR}$ tablets } & 0.3 & 0.2974 & 99.14 & 99.23 \\
\hline & 0.7 & 0.6981 & 99.72 & 99.61 \\
\hline & 1.0 & 1.0094 & 100.94 & 100.61 \\
\hline & 3.0 & 3.0036 & 100.12 & \\
\hline & 5.0 & 4.9835 & 99.67 & \\
\hline & 6.0 & 5.9844 & 99.74 & \\
\hline $\mathrm{X}^{-} \pm \mathrm{SD}$ & & & $99.88 \pm 0.61$ & $99.82 \pm 0.71$ \\
\hline Student's $\mathrm{t}$ test & & & $0.39(2.02)^{*}$ & \\
\hline Variance ratio $\mathrm{F}$ test & & & $1.35(3.78)^{*}$ & \\
\hline \multirow[t]{6}{*}{ Evastine $^{\circledR}$ syrup } & 0.3 & 0.30216 & 100.72 & 100.12 \\
\hline & 0.7 & 0.69615 & 99.45 & 99.61 \\
\hline & 1.0 & 1.0011 & 100.11 & 99.51 \\
\hline & 3.0 & 3.0144 & 100.48 & \\
\hline & 5.0 & 5.031 & 100.62 & \\
\hline & 6.0 & 5.9994 & 99.99 & \\
\hline $\mathrm{X}^{-} \pm \mathrm{SD}$ & & & $100.23 \pm 0.48$ & $99.75 \pm 0.33$ \\
\hline Student's $\mathrm{t}$ test & & & $0.23(2.02)^{*}$ & \\
\hline Variance ratio $\mathrm{F}$ test & & & $2.12(3.78)^{*}$ & \\
\hline
\end{tabular}

*Figures between parentheses are the tabulated $t$ and $F$ values at $p=0.05[20] . *$ 
consuming process when using conventional assay technique. The steps of the test were adopted according to the United States Pharmacopoeia [17] procedure. The acceptance value AV was calculated for each of the commercially available tablets and it was found to be smaller than the maximum allowed acceptance value L1. The results demonstrated reasonable drug uniformity as shown in Table 6.

\section{Interferences}

Many drugs which are frequently co- administered with EBS such as erythromycin and ketoconazole were carefully tested. The studied drugs were found to be adequately separated from the formed complex (Figures 7 a, b).

\section{Forced degradation studies of EBS}

In order to establish whether the analytical method was stability indicating, EBS was stressed under various conditions to contact forced degradation studies [16]. Methanol was used as a co-solvent in all forced degradation studies.

\section{Degradation kinetics study}

For the kinetic study, $2 \mathrm{M}$ sodium hydroxide was used for alkaline degradation of the drug. Regarding the UV degradation, the methanolic solution of EBS was exposed to Deuterium lamp in a wooden cabinet distance of $15 \mathrm{~cm}$ for different time intervals.

The apparent decrease in the peak area ratios of EBS upon alkaline degradation with $2 \mathrm{M}$ sodium hydroxide in

Table 6 Content uniformity testing of ebastine in its dosage forms using the proposed method

\begin{tabular}{ccc}
\hline Parameter & \multicolumn{2}{c}{ Percentage of the label claim } \\
\hline Data & Bastab $^{\circledR}$ tablets & Ebastel $^{\circledR}$ tablets \\
\cline { 2 - 3 } & 100.25 & 100.67 \\
\cline { 2 - 3 } & 101.12 & 99.64 \\
\cline { 2 - 3 } & 100.65 & 99.18 \\
\cline { 2 - 3 } & 99.81 & 100.66 \\
\cline { 2 - 3 } & 99.54 & 100.82 \\
\cline { 2 - 3 } & 100.91 & 101.11 \\
\cline { 2 - 3 } & 99.34 & 99.37 \\
\hline Mean X & 100.55 & 99.42 \\
\hline SD & 101.18 & 100.68 \\
\hline \%Error & 99.45 & 99.35 \\
\hline Acceptance value (AV) & 100.28 & 100.09 \\
\hline Maximum allowed value (L1) & 0.704 & 0.754 \\
\hline
\end{tabular}

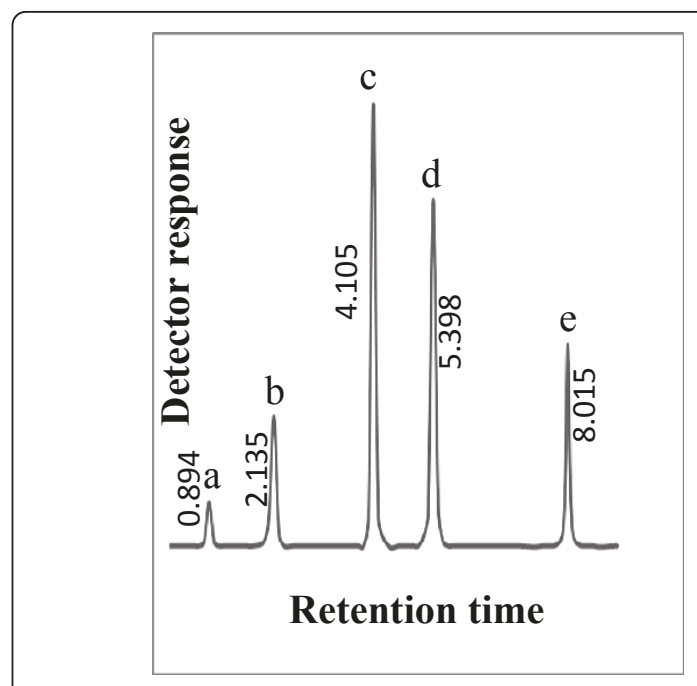

A

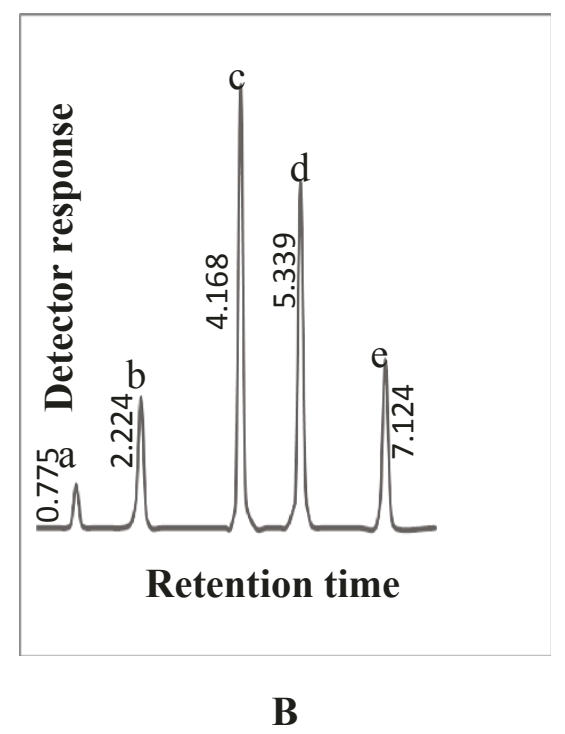

Figure 7 Typical chromatograms of EBS- $\mathrm{Zn}^{2+}$ complex in presence of co-administered drugs. A. Typical chromatogram showing EBS-Zn (II) complex in presence of erythromycin where: a) Solvent front b) Zn (II) $0.0025 \%$ c) Cetirizine hydrochloride internal standard $(15 \mu \mathrm{g} / \mathrm{ml})$. d) Ebastine - Zn (II) complex; (EBS = 4 $\mu \mathrm{g} / \mathrm{ml})$ e) Erythromycin $(20 \mu \mathrm{g} / \mathrm{ml})$ B. Typical chromatogram showing EBS-Zn (II) complex in presence of ketoconazole where: a) Solvent front b) Zn (II) $0.0025 \%$ c) Cetirizine hydrochloride internal standard $(15 \mu \mathrm{g} / \mathrm{ml})$. d) Ebastine - Zn (II) complex; (EBS = 4 $\mu \mathrm{g} / \mathrm{ml})$ e) Ketoconazole $(20 \mu \mathrm{g} / \mathrm{ml})$

a boiling water bath, and under UV lamp at different time intervals are demonstrated in Figures 8 (I-IV) and 9 (I-IV).

The degradation was found to be temperature dependant (Figures 10 and 11). Regarding the alkaline 

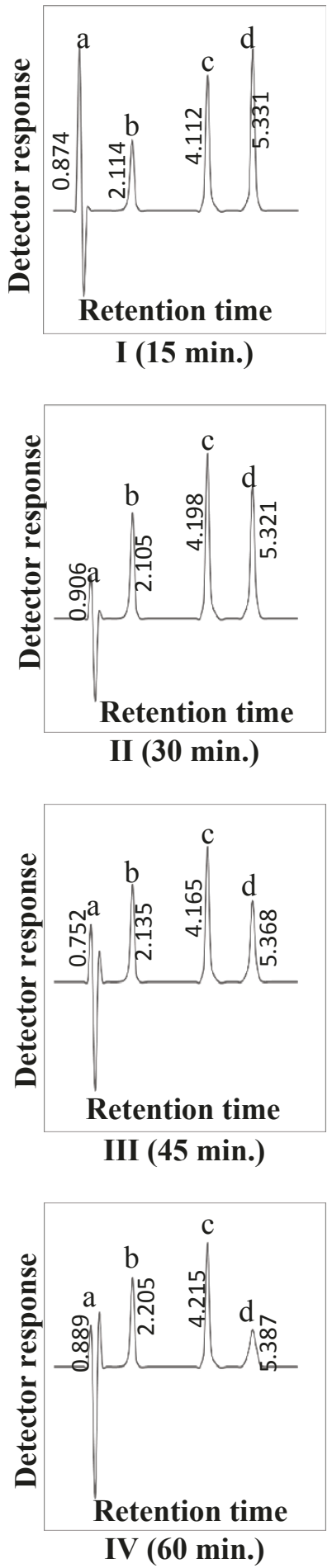

Figure 8 (I-IV) Typical chromatograms showing the decrease in peak area ratios of EBS- Zn (II) complex by alkaline

degradation at different time intervals where: a) Solvent front b) Zn (II) $0.0025 \%$ c) Cetirizine hydrochloride internal standard (15 $\mu \mathrm{g} /$ ml). d) Ebastine- Zn (II) complex
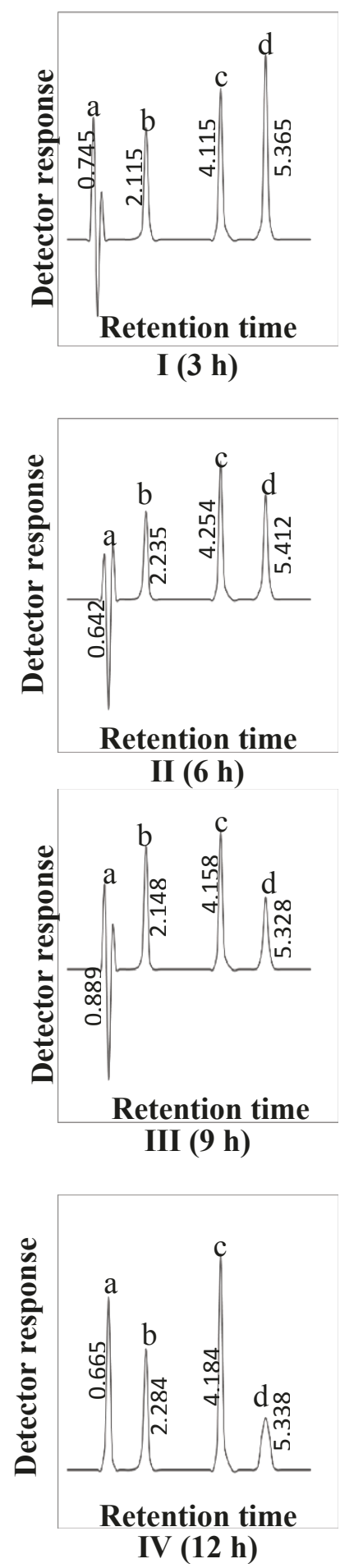

Figure 9 (I-IV) Typical chromatograms showing the decrease in peak area ratios of EBS- Zn (II) complex by UVdegradation at different time intervals where: a) Solvent front b) Zn (II) $0.0025 \%$ c) Cetirizine hydrochloride internal standard $(15 \mu \mathrm{g} / \mathrm{ml})$. d) EbastineZn (II) complex 


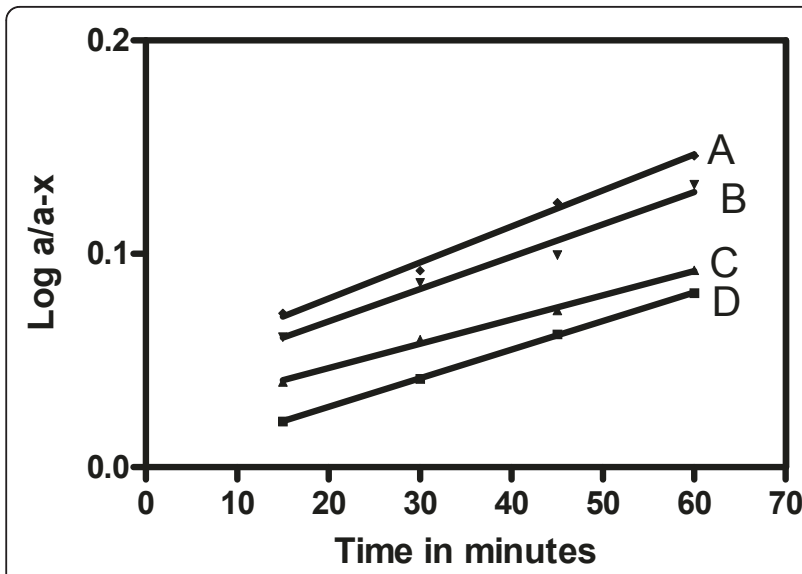

Figure 10 Semilogarithmic plot of EBS $(4 \mu \mathrm{g} / \mathrm{ml})$ versus different heating times with $2 \mathrm{M} \mathrm{NaOH} .\left(\mathrm{A}=80^{\circ} \mathrm{C}, \mathrm{B}=70^{\circ} \mathrm{C}, \mathrm{C}=\right.$ $60^{\circ} \mathrm{C}$, and $\mathrm{D}=50^{\circ} \mathrm{C}$ ).

degradation, the first order degradation rate constant and the half life time at each temperature were calculated (Table 7) according to the following equations:

$\ln \mathrm{a} / \mathrm{a}-\mathrm{x}=\mathrm{Kt}$ where $\mathrm{a}$ is the initial concentration of the drug, $x$ is the concentration of the resulting degraded solution after time $t$, and $K$ is the reaction rate constant

While the half life time could be calculated as follows: $\mathrm{t}_{1 / 2}=0.693 / \mathrm{K}$.

Plotting $\log \mathrm{K}_{\mathrm{obs}}$ values versus $1 / \mathrm{T}$, the Arhenius plot was obtained (Figure 12). The activation energy was also calculated by the equation:

$\ln \mathrm{K}=-\mathrm{Ea} / \mathrm{RT}+\ln \mathrm{A}$ where: $\mathrm{Ea}$ is the activation energy, $\mathrm{K}$ is first order reaction rate constant, $\mathrm{R}$ is the gas constant, and $\mathrm{T}$ is the temperature in kelvin.

On the other hand, the proposed method did not indicate either the acidic or the oxidative degradation of

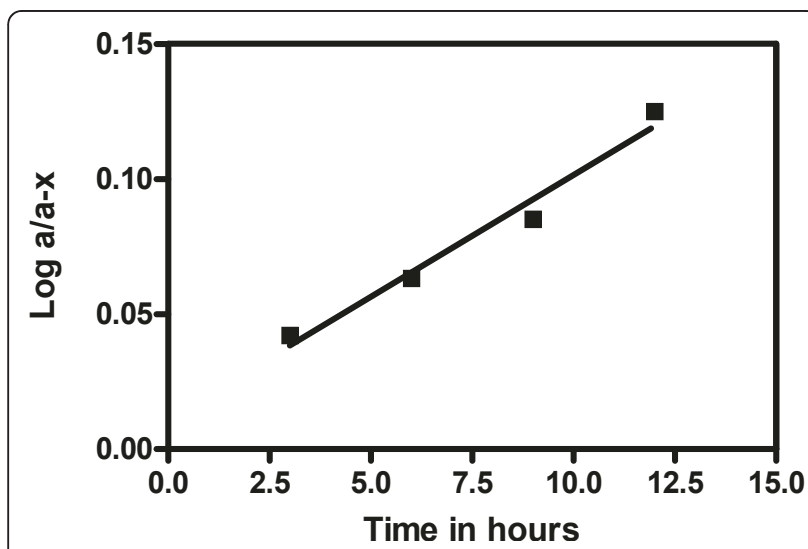

Figure 11 Semilogarithmic plot of EBS $(4 \mu \mathrm{g} / \mathrm{ml})$ versus different times under UV lamp.
Table 7 Effect of temperature on the kinetic parameters of EBS

\begin{tabular}{ccc}
\hline Temperature $\left({ }^{\circ} \mathbf{C}\right)$ & $\mathbf{K}\left(\mathbf{m i n}^{-1}\right)$ & $\mathbf{t}_{\mathbf{1 / 2}}$ (min.) \\
\hline $\mathbf{5 0}$ & 0.001137 & 609 \\
\hline $\mathbf{6 0}$ & 0.00134 & 517 \\
\hline $\mathbf{7 0}$ & 0.001515 & 421 \\
\hline $\mathbf{8 0}$ & 0.001691 & 410 \\
\hline $\mathbf{E a}=\left(\mathrm{K}_{\left.\text {Cal. } \mathrm{mol}^{-1}\right)}\right.$ & & \\
\hline
\end{tabular}

ebastine. In both cases, the peak corresponding for the complex did not appear in the chromatogram, pointing out that the degradation step altered the chemical moiety responsible for the complexation between EBS and $\mathrm{Zn}$ (II). The acidic degradation is supposed to act on the basic centre of the studied drug; teriary amine, which is involved in the complex formation, and hence, the complex will be no further be formed. While, the oxidative degradation carried out with $6 \%$ hydrogen peroxide may cause the oxidation of the tertiary amino group to the $\mathrm{N}$-oxide derivative, and subsequently alter the complex formation.

\section{Conclusion}

A simple, sensitive and rapid HPLC method has been developed for the determination of ebastine in its pharmaceuticals. The sensitivity of the proposed method allows its application for content uniformity testing. Extensive study concerning the composition and stability of the complex was also conducted. Another advantage of the studied method is its stability indicating property which was utilized to investigate the kinetics of alkaline and ultraviolet induced degradation of the drug. Validation was carefully stu-

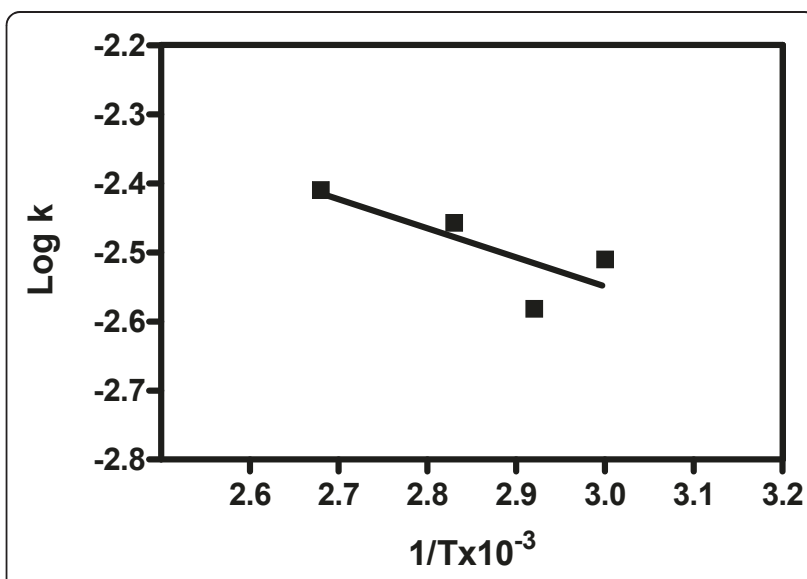

Figure 12 Arrhenius plot for the degradation of EBS $(4 \mu \mathrm{g} / \mathrm{ml})$ in $2 \mathrm{M} \mathrm{NaOH}$. 
died to elicit an assay which can be used in routine quality control laboratories.

\section{Acknowledgements}

This work was financially supported by Faculty of pharmacy, Mansoura University

\section{Authors' contributions}

FI designed the proposed method and analyzed the data statistically. MKSE proposed, planned and supervised the whole work. MIE coordinated the study and modified the text. MEKW carried out the experimental work. All authors read and approved the final manuscript.

\section{Competing interests}

The authors declare that they have no competing interests.

Received: 15 March 2011 Accepted: 9 May 2011 Published: 9 May 2011

\section{References}

1. Sweetman S: Martindale: The complete drug reference. Pharmaceutical press: London; 352006.

2. Ibrahim F, El-Din MK, Eid Ml, Wahba ME: Validated stability-indicating spectrofluorimetric methods for the determination of ebastine in pharmaceutical preparations. Chem Cent J 2011, 5:11.

3. Arend MZ, Cardoso SG, Hurtado FK, Ravanello A, Lanzanova FA: Development and Validation of a Stability-Indicating LC Method for Determination of Ebastine in Tablet and Syrup. Chromatographia 2009, 69:195-199.

4. Prabu SL, Kumar CD, Shirwaikar A, Shirwaikar A: Determination of ebastine in pharmaceutical formulations by HPLC. Indian J Pharm Sci 2008, 70:406-407.

5. Kang W, Liu KH, Ryu JY, Shin JG: Simultaneous determination of ebastine and its three metabolites in plasma using liquid chromatographytandem mass spectrometry. J Chromatog B 2004, 813:75-80.

6. Matsuda M, Mizuki $Y$, Terauchi $Y$ : Simultaneous determination of the histamine $\mathrm{H}_{1}$-receptor antagonist ebastine and its two metabolites, carebastine and hydroxyebastine, in human plasma using highperformance liquid chromatography. J Chromatog B 2001, 757:173-179.

7. Stalikas CD, Fiamegos YC: Microextraction combined with derivatization. Trends in Anal Chem 2008, 27:533-542.

8. Petsch M, Seipelt J, Mayer-Helm BX: A novel pre-column derivatization reaction for the determination of dithiocarbamates in plasma by highperformance liquid chromatography. Anal Chim Acta 2004, 516:119-124.

9. Rizk M, Belal F, Ibrahim F, Ahmed S, Sheribah ZA: LC of pharmaceutically important halogenated 8-hydroxyquinolines after precolumn derivatization with Pd (II). J Pharm Biomed Anal 2002, 27:813-820.

10. Toida T, Shima M, Azumaya S, Maruyama T, Toyoda H, Imanari T, Linhardt RJ: Detection of glycosaminoglycans as a copper(II) complex in high-performance liquid chromatography. J Chromatog A 1997, 787:266-270

11. Rogers ME, Adlard MW, Saunders G, Holt G: Derivatization techniques for high-performance liquid chromatographic analysis of $\beta$-lactams. $J$ Chromatog A 1984, 297:385-391.

12. Leroy $P$, Nicolas $A$ : Determination of secondary amino drugs as their metal dithiocarbamate complexes by reversed-phase high-performance liquid chromatography with electrochemical detection. J Chromatog A 1984, 317:513-521.

13. Heyrovsky J, Zuman P: Practical Polarography. Academic press: London; 1968.

14. British Pharmacopoeia Commission: The British Pharmacopoeia. The Stationary Office: London; 2007.

15. O'Neil MJ: The Merck Index, an Encyclopedia of Chemicals, Drugs, and Biologicals. Merck \& Co., Inc. :Whitehouse Station, NJ i, 132001.

16. Guidance for industry; Q2B of analytical procedure: Methodology. International Conference on Hormonization (ICH), November; 2005 [http:// www.fda.gov/downloads/Drugs/ GuidanceComplianceRegulatoryInformation/Guidances/ucm073384.pdf].

17. United States Pharmacopeial Convention: United States Pharmacopoeia 30; National Formulary 25. US Pharmacopoeia Convention: Rockville, MD; 2007.
18. Sawyer DT, Heineman WR, Beebe JM: Chemistry Experiments for Instrumental Method. Wiley, New York; 1984, 198-200.

19. Inczedy J: Analytical and Application of Complex Equilibria. John Wiley and Sons Inc. :Buda Pest; 1976, p101.

20. Miller JC, Miller JN: Statistics for analytical chemistry. Wiley :New York; 2005, p256.

doi:10.1186/1752-153X-5-24

Cite this article as: Ibrahim et al:: Validated stability indicating liquid chromatographic determination of ebastine in pharmaceuticals after pre column derivatization: Application to tablets and content uniformity testing. Chemistry Central Journal 2011 5:24.

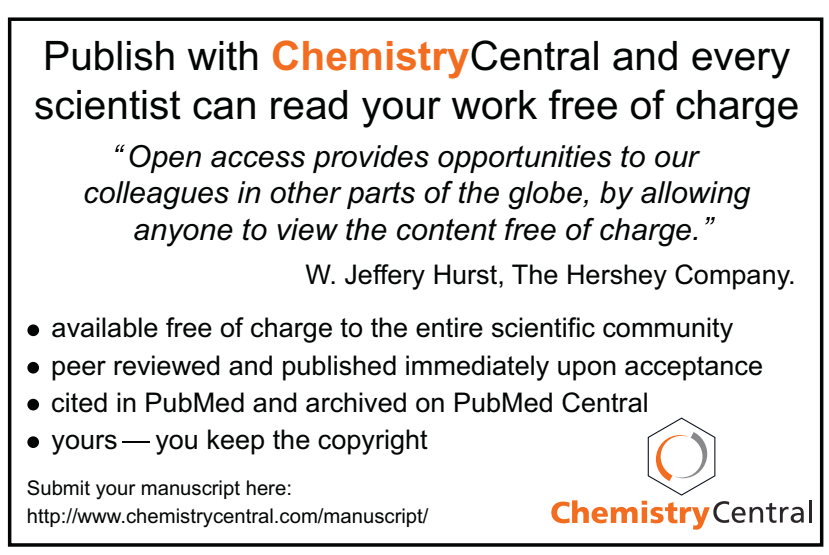

